\title{
A Biologically Inspired Cu(I)/Topaquinone-Like Co-Catalytic System for the Highly Atom Economical Aerobic Oxidation of Primary Amines to Imines
}

\author{
Martine Largeron*, and Maurice-Bernard Fleury
}

Imines are versatile synthetic intermediates in a variety of organic transformations and are essential pharmacophores in numerous biologically active compounds. ${ }^{[1]}$ Great progress has been made in the past decade for the synthesis of imines, including oxidation of secondary amines, ${ }^{[2]}$ oxidative self- or crosscoupling of primary amines, ${ }^{[3]}$ and direct synthesis from amines and alcohols in the presence of catalyst. ${ }^{[4]}$ However, most of the methods suffer some limitations such as prolonged reaction times, high reaction temperatures, environmentally unfriendly oxidants or low selectivity. Furthermore, metal-catalyzed oxidation reactions often utilize expensive and limited available precious metals such as palladium, ruthenium, gold, iridium and vanadium. Consequently, the development of new efficient environmentally benign procedures for the synthesis of imines continues to be a challenging and active area of research. ${ }^{[5]}$

Simulation of the functions of amine oxidase enzymes that govern the metabolism of amines may also lead to the development of biomimetic catalytic oxidation of amines to imines under mild conditions. ${ }^{[6]}$ In this respect, we recently found that electrogenerated $o$-iminoquinone species $\mathbf{1}_{\mathbf{o x}}$ (step 1, Scheme 1) was able to replicate the activity and specificity of copper-containing amine oxidases (CuAOs) enzymes toward primary amines. ${ }^{[7]}$ The catalytic cycle produced $N$-alkylidenealkylamine as the product of amine oxidation through the ionic pyridoxal-like transamination process reported for CuAOs (Scheme 1). The rate limiting step involves $\alpha$-proton abstraction and the subsequent electron flow from the $\alpha$-carbon to the $o$-iminoquinone moiety which aromatizes to the highly reactive Schiff base cyclic transition state 1'ox (step 4, Scheme 1) thus allowing the activation of the imine function for further nucleophilic attack by the amine (step 5, Scheme 1). ${ }^{[7 \mathrm{~b}]}$ This $\mathbf{1}_{\mathbf{o x}}$-mediated electrocatalytic oxidation of primary amines allowed the generation of unstable imines (step 6, Scheme 1), under metal-free conditions, without any stoichiometric reagents, at ambient atmosphere. These conditions are particularly favorable for using the imine in situ for further reactions. For example, we have recently developed a facile one-pot metal-free $\mathbf{1}_{\text {ox }}$-mediated oxidation-imine formation-reduction sequence for the atom-economical chemoselective $\mathrm{N}$-alkylation of benzylic primary amines with amines, allowing the synthesis of benzylic secondary amines, under mild

[*] Dr. M. Largeron, Prof. Dr. M.-B. Fleury

Université Paris Descartes

UMR CNRS 8638

4, avenue de l'Observatoire, 75270 Paris Cedex 06 (France)

Fax : (+33) 0144073588

E-mail : martine.largeron@parisdescartes.fr

Supporting information for this article is available on the WWW under http://www.angewandte.org or from the author. 
conditions. ${ }^{[8]}$

Nevertheless, it seemed doubtful that our electrochemical procedure ${ }^{[7]}$ will ever be able to compete with more conventional chemical approaches at a large preparative scale. In contrast, the process would be most attractive if $\mathbf{1}_{\mathbf{o x}}$ could be generated through aerobic oxidation of $\mathbf{1}_{\text {red. }}$ So, inspired by the enzymatic reaction of $\mathrm{CuAOs},{ }^{[9]}$ and by recent breakthroughs on the aerobic oxidation of amines to imines, ${ }^{[5,6]}$ we demonstrate herein that a synergistic combination of copper and organocatalyst $\mathbf{1}_{\mathbf{0 x}}$ constitutes a novel approach to imines from primary amines, under very mild conditions that are dioxygen in air as the oxidant together with ambient temperature and pressure.

Based on the efficient reactivity between electrocatalyst $\mathbf{1}_{\mathbf{o x}}$ and various amines, ${ }^{[7]}$ we hypothesized that the oxidation process started with atmospheric oxygen as reported in Scheme 2, and continued in a cascade-like manner by passing its oxidation potential through copper salt to the organic $o$-iminoquinone mediator $\mathbf{1}_{\mathbf{o x}}$, which finally oxidized the amine substrate after forming the Schiff base cyclic transition state 1'ox (step 4, Scheme 1). To evaluate the validity of this concept, we began our investigations with benzylamine as the amine substrate. If our hypothesis is right, part of the optimum conditions should be identical to that required for the electrochemical process. Accordingly, $\mathrm{MeOH}$ was preferred over other solvents such as THF, $\mathrm{MeCN}$ or $\mathrm{CHCl}_{3}$, because strong solvation of the $o$-iminoquinone $\mathbf{1}_{\mathbf{0 x}}$ by $\mathrm{MeOH}$ was necessary to enhance the electrophilicity of its quinonoid moiety, thereby favoring the nucleophilic attack (step 2, Scheme 1) of amine. Likewise, a combination of 1 equiv of amine with 0.02 equiv of $\mathbf{1}_{\text {red }}{ }^{[10]}$ which corresponds to $2 \mathrm{~mol} \%$ of organocatalyst $\mathbf{1}_{\mathbf{o x}}$, was found to be ideal for the reaction. ${ }^{[7 \mathrm{~b}]} \mathrm{In}$ the absence of copper catalyst, the reaction proceeded very slowly, and the conversion of benzylamine into $N$-benzylidenebenzylamine reached $66 \%$ in 7 days, owing to the slow spontaneous aerobic oxidation of $\mathbf{1}_{\text {red. }}$ When, in turn, $0.2 \mathrm{~mol} \%$ of copper (I) 3-methylsalicylate (CuMeSal) was added as the co-catalyst ( 0.002 equiv), only $10 \mathrm{~h}$ were needed for full conversion of benzylamine ( $85 \%$ conversion after $3 \mathrm{~h})$. Then, $N$-benzylidenebenzylamine was isolated in $96 \%$ yield as the sole product (as observed by ${ }^{1} \mathrm{H}$ NMR spectroscopy), after evaporation of the solvent at ambient temperature. No improvements were observed when $\mathrm{Cu}$ (I) loading was increased. Different copper catalysts such as $\mathrm{CuI}$ and $\mathrm{Cu}(\mathrm{OAc})_{2}$ were also screened. All the copper salts catalyzed the reaction but a reduction of reaction time was observed with CuMeSal. In a separate control experiment, $\mathbf{1}_{\text {red }}$ was fully omitted from the reaction mixture. Then, no reaction occurred at room temperature when copper was used as the sole catalyst. ${ }^{[5 \mathrm{~d}, \mathrm{e}]}$ Interestingly, monitoring the progress of the synergistic catalytic process in MeOD by ${ }^{1} \mathrm{H}$ NMR analysis revealed that only $N$-benzylidenebenzylamine was formed, with no evidence for the formation of benzaldehyde, a result in agreement with the formation of the Schiff base intermediate 1' ox $_{\text {, a }}$ reported in Scheme 1 (step 4).

Next, the scope of the biomimetic $\mathrm{Cu}(\mathrm{I}) / \mathbf{1}_{\mathbf{o x}}$ co-catalytic system was examined with regard to a range of structurally diverse primary amines. High catalytic activity was found for the conversion of benzylic 
amines (Table 1, entries 1-8), and the imine product yield did not markedly depended on the substitution of the phenyl ring. In particular, halo-substituted benzylamines (entries 2 and 3) performed well, leading to halo-substituted imines which could be used for further transformations along with the imine functionality. It should be noted that this approach was also applicable to heteroatom-containing amine substrates such as thiophene (entry 9) and furan (entry 10), whose imine products are usually inaccessible by transition-metal complex catalysis because of deactivation of the catalysts caused by the strong coordination of these amines to the metal center. The synthesis of aliphatic imines is inherently more challenging because of their instability and difficult isolation. Therefore, the possibility of expanding the scope of this novel method to the synthesis of aliphatic imines was also explored (entries 11-13). Although $N$-alkylidenealkylamine could be observed during the first hours of the reaction through ${ }^{1} \mathrm{H}$ NMR spectrum monitoring (see the Supporting Information Data), its instability did not permit to isolate it as such. Consequently, the yield was obtained by conversion to the 2,4-dinitrophenylhydrazone (DNPH) by aqueous acidic work-up of the reaction mixture with 2,4-dinitrophenylhydrazine. ${ }^{\text {[7b] }}$ Interestingly, as for the CuAOs enzymes, $\alpha$-branched amines (entry 14) were found to be inferior substrates for the biomimetic $\mathrm{Cu}(\mathrm{I}) / \mathbf{1}_{\mathbf{0 x}}$ co-catalytic system, whereas secondary amines were not reactive at all (entry 15).

In subsequent studies, we attempted the synthesis of cross-coupling products A by reacting 4methylbenzylamine in the presence of different primary amines (Table 2). The real-time monitoring of the reaction between 4-methylbenzylamine and aminomethylcyclohexane (equimolar amounts) by ${ }^{1} \mathrm{H}$ NMR analysis indicated that both self-coupling product $\mathbf{B}$ (singlet around $8.40 \mathrm{ppm}$ ) and cross-coupling product A (singlet around $8.20 \mathrm{ppm}$ ) were initially formed, with a preference for homo-coupling product B (See Figure 1 in the Supporting Information Data, spectra a and b). However, after 30 min, imine B gradually turned to cross-coupling product $\mathbf{A}$, which finally became the major product after $10 \mathrm{~h}$ (spectra $\mathrm{c}$ and $\mathrm{d}$, Figure 1). From these results, we envision two different pathways. First, homo-coupling product $\mathbf{B}$ is extruded as the sole imine product through reaction scheme 1 , and further $N$-alkylated by the second primary amine. In this case, copper could promote reaction of the homo-coupling product $\mathbf{B}$ with the alkylating primary amine via addition-elimination mechanism leading to the cross-coupling product $\mathbf{A}$. Second, both homo- and cross-coupling products are produced competitively through reaction scheme 1 (steps 5 and 6). At this point, it seems that the formation of the cross-coupling product A would preferably result from the nucleophilic attack of the Schiff base intermediate 1' the alkylating aliphatic primary amine. Accordingly, the presence of an excess of the alkylating primary amine (2 equiv) did not increase the amount of cross-coupling product A versus that of homo-coupling product $\mathbf{B}$, and 4-methylbenzaldehyde has never been observed during the catalytic process. As shown in Table 2, a good imines selectivity was observed in all cases. Note $\mathrm{Cu}(\mathrm{I}) / \mathbf{1}_{\mathbf{o x}}$-catalyzed aerobic oxidative 
imination of 4-methylbenzylamine by ethanolamine showed good tolerance of alcohol functional group (entry 8, Table 2).

In conclusion, we have achieved chemoselective biologically inspired $\mathrm{Cu}(\mathrm{I}) / \mathbf{1}_{\text {ox }}$-mediated aerobic oxidation of primary amines. Low catalytic amounts of biocompatible $\mathrm{Cu}(\mathrm{I})$ metal-catalyst $(0.2 \mathrm{~mol} \%)$ and $\mathbf{1}_{\mathbf{o x}}$ organocatalyst $(2 \mathrm{~mol} \%$ ) are sufficient to activate the $\alpha-\mathrm{C}-\mathrm{H}$ bond of primary amines which are converted into alkylated imines under ambient conditions. This atom-economical green process tolerates the presence of various reactive functional groups and is highly selective in the case of cross-coupling of two amines. Studies are underway in our laboratory to investigate further synthetic applications.

\section{Experimental Section}

$N$-Benzylidenebenzylamine. ${ }^{[11]}$ Typical procedure: Benzylamine $(5$ mmol, 1 equiv $)$ reduced organocatalyst $\mathbf{1}_{\text {red }}\left(0.1 \mathrm{mmol}, 0.02\right.$ equiv), ${ }^{[10]}$ and copper 3 -methylsalicylate $(0.01 \mathrm{mmol}, 0.002$ equiv) were mixed in $\mathrm{MeOH}(10 \mathrm{~mL})$ in an air atmosphere. The reaction mixture was stirred at room temperature for $10 \mathrm{~h}$. The progress of the reaction was monitored by ${ }^{1} \mathrm{H}$ NMR spectroscopy. After completion of the reaction, the solvent was evaporated at room temperature giving $\mathrm{N}$ Benzylidenebenzylamine as an almost pure product, whose identity and purity were confirmed by ${ }^{1} \mathrm{H}$ and ${ }^{13} \mathrm{C}$ NMR spectroscopy, after comparison with an authentic sample.

Keywords: amine $\cdot$ chemoselectivity $\cdot$ imine $\cdot$ oxidation $\cdot$ synergistic catalysis $\cdot$

\section{References}

[1] For a review on the synthesis of imines see: J.P. Adams, J. Chem. Soc. Perkin Trans. 1 2000, 2, 125-139.

[2] For selected recent examples, see: a) K. C. Nicolaou, C. J. N. Mathison, T. Montagnon, Angew. Chem. 2003, 115, 4111-4117; Angew. Chem. Int. Ed. 2003, 42, 4077-4082; b) K. Yamaguchi, N. Mizuno, Angew. Chem. 2003, 115, 1518-1521; Angew. Chem. Int. Ed. 2003, 42, 1480-1483; c) K. C. Nicolaou, C. J. N. Mathison, T. Montagnon, J. Am. Chem. Soc. 2004, 126, 5196-5201; d) J. W. Wang, Y. Fu, B.-B. Zhang, X. Cui, L. Liu, Q.-X. Guo, Tetrahedron Lett. 2006, 8293-8297; e) H. Choi, M.P. Doyle, Chem. Commun. 2007, 745-747; f) N. Mizuno, K. Yamaguchi, Catal. Today 2008, 132, 18-26; g) G. Jiang, J. Chen, J.-S. Huang, C.-M. Che, Org. Lett. 2009, 11, 4568-4571; h) R. Yamaguchi, C. Ikeda, Y. Takahashi, K.-I. Fugita, J. Am. Chem. Soc. 2009, 131, 8410-8412.

[3] a) S. I. Murahashi, Y. Okano, H. Sato, T. Nakae, N. Komiya, Synlett 2007, 1675-1678; b) B. Zhu, M. Lazar, B.-G. Trewyn, R.-J. Angelici, J. Catal. 2008, 260, 1-6; c) L. Aschwanden, T. Mallat, F. Krumeich, 
A. Baiker, J. Mol. Catal. A: Chem. 2009, 309, 57-62; d) M.-H. So, Y. Liu, C.-M. Ho, C.-M. Che, Chem. Asian. J. 2009, 4, 1551-1561; e) A. Dhakshinamoorthy, M. Alvaro, H. Garcia, Chem. Cat. Chem. 2010, 2, 1438-1443; f) S. Kodama, J. Yoshida, A. Nomoto, Y. Ueta, S. Yano, M. Ueshima, A. Ogawa, Tetrahedron Lett. 2010, 51, 2450-2452; g) W. He, L. Wang, C. Sun, K. Wu, S. He, J. Chen, P. Wu, Z. Yu, Chem. Eur. J. 2011, 17, 13308-13317.

[4] a) L. Blackburn, R. J. K. Taylor, Org. Lett. 2001, 3, 1637-1639; b) M.S. Kwon, S. Kim, S. Park, W. Bosco, R. K. Chidrala, J. Park, J. Org. Chem. 2009, 74, 2877-2879; c) J. W. Rigoli, S. A. Moyer, S. D. Pearce, J. M. Schomaker, Org. Biomol. Chem. 2012, 10, 1746-1749.

[5] For recent environmentally benign new methods, see: a) J. Srogl, S. Voltrova, Org. Lett. 2009, 11, 843-845; b) B. Gnanaprakasam, J. Zhang, D. Milstein, Angew. Chem. 2010, 122, 1510-1513; Angew. Chem. Int. Ed. 2010, 49, 1468-1471; c) G. Chu, C. Li, Org. Biomol. Chem. 2010, 8, 4716-4719; d) R. D. Patil, S. Adimurthy, Adv. Synth. Catal. 2011, 353, 1695-1700; e) L. Liu, S. Zhang, X. Fu, C.-H. Yan, Chem. Commun. 2011, 47, 10148-10150; f) X. Lang, H. Ji, C. Chen, W. Ma, J. Zhao, Angew. Chem. 2011, 123, 4020-4023; Angew. Chem. Int. Ed. 2011, 50, 3934-3937; g) L. Jiang, L. Jin, H. Tian, X. Yuan, X. Yu, Q. Xu, Chem. Commun. 2011, 47, 10833-10835; h) Y. Shiraishi, M. Ikeda, D. Tsukamoto, S. Tanaka, T. Hirai, Chem. Commun. 2011, 47, 4811-4813; i) Z. Hu, F. M. Kerton, Org. Biomol. Chem. 2012, 10, 1618-1624; j) X. Lang, W. Ma, Y. Zhao, C. Chen, H. Ji, J. Zhao, Chem. Eur. J. 2012, 18, 2624-2631.

[6] For recent reviews, see: a) M. Mure, Acc. Chem. Res. 2004, 37, 131-139; b) J. Piera, J. E. Bäckvall, Angew. Chem. 2008, 120, 3558-3576; Angew. Chem. Int. Ed. 2008, 47, 3506-3523. See also: c) A. H. Ell, J. S. M. Samec, C. Brasse, J. E. Bäckvall, Chem. Commun. 2002, 1144-1145; d) J. S. M. Samec, A. H. Ell, J. E. Bäckvall, Chem. Eur. J. 2005, 11, 2327-2334.

[7] a) M. Largeron, A. Neudörffer, M.-B. Fleury, Angew. Chem. 2003, 115, 1056-1059; Angew. Chem. Int. Ed. 2003, 42, 1026-1029; b) M. Largeron, A. Chiaroni, M.-B. Fleury, Chem. Eur. J. 2008, 14, 996-1003; c) M. Largeron, M.-B. Fleury, M. Strolin Benedetti Org. Biomol. Chem. 2010, 8, 3796-3800.

[8] a) M. Largeron, M.-B. Fleury, Org. Lett. 2009, 11, 883-886; b) M. Largeron, Electrochim. Acta, 2009, $54,5109-5115$.

[9] S. Suzuki, T. Okajima, K. Tanizawa, M. Mure in Copper Amine Oxidases. Structures, Catalytic Mechanisms, and Role in Pathophysiology (Eds.: G. Floris, B. Mondovi), CRC Press, Taylor and Francis Group Publishing, New York, 2009, p19.

[10]Reduced catalyst $\mathbf{1}_{\text {red }}$ can be easily prepared in two steps from commercially available 2-nitroresorcinol, according to our published procedure: D. Xu, A. Chiaroni, M.-B. Fleury, M. Largeron, J. Org. Chem. 2006, 71, 6374-6381 (See the supporting information). 
[11]P. G. M. Wuts, Y.-W. Jung, J. Org. Chem. 1991, 56, 365-372. 
Table 1. Aerobic $\mathrm{Cu}(\mathrm{I}) / \mathbf{1}_{\text {ox }}$-catalyzed oxidation of different amines. ${ }^{\left[{ }^{[a]}\right.}$

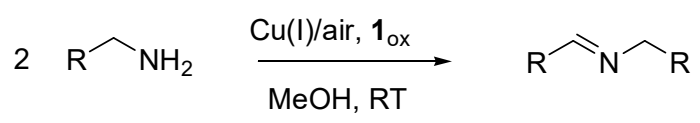

Entry Substrate $\quad$ Product $\quad$ Yield $^{[\mathrm{b}]}$

[\%]

(n)

[a] Reagents and conditions: (amine substrate) $=20 \mathrm{mM} ;\left(1_{\mathrm{ox}}\right)=0.4 \mathrm{mM}(2 \mathrm{~mol} \%$ relative to amine $) ; \mathrm{Cu}(\mathrm{I}):$ copper $(\mathrm{I})-3-\mathrm{methylsalicylate}=0.04$ $\mathrm{mM}(0.2 \mathrm{~mol} \%$ relative to amine); $10 \mathrm{~mL}$ of $\mathrm{MeOH}, 10 \mathrm{~h}, \mathrm{RT}$. [b] Yields of the imine refer to the isolated unpurified product which, unless otherwise stated, was pure by ${ }^{1} \mathrm{H}$ NMR spectroscopy (see the Supporting Information). [c] Imine product directly precipitated in the bulk solution. [d] Yields obtained by conversion to the corresponding DNPH by aqueous acidic work-up of the reaction mixture with 2,4dinitrophenylhydrazine. 
Table 2. Aerobic $\mathrm{Cu}(\mathrm{I}) / \mathbf{1}_{\text {ox }}$-catalyzed oxidative cross-coupling of amines. ${ }^{[a]}$

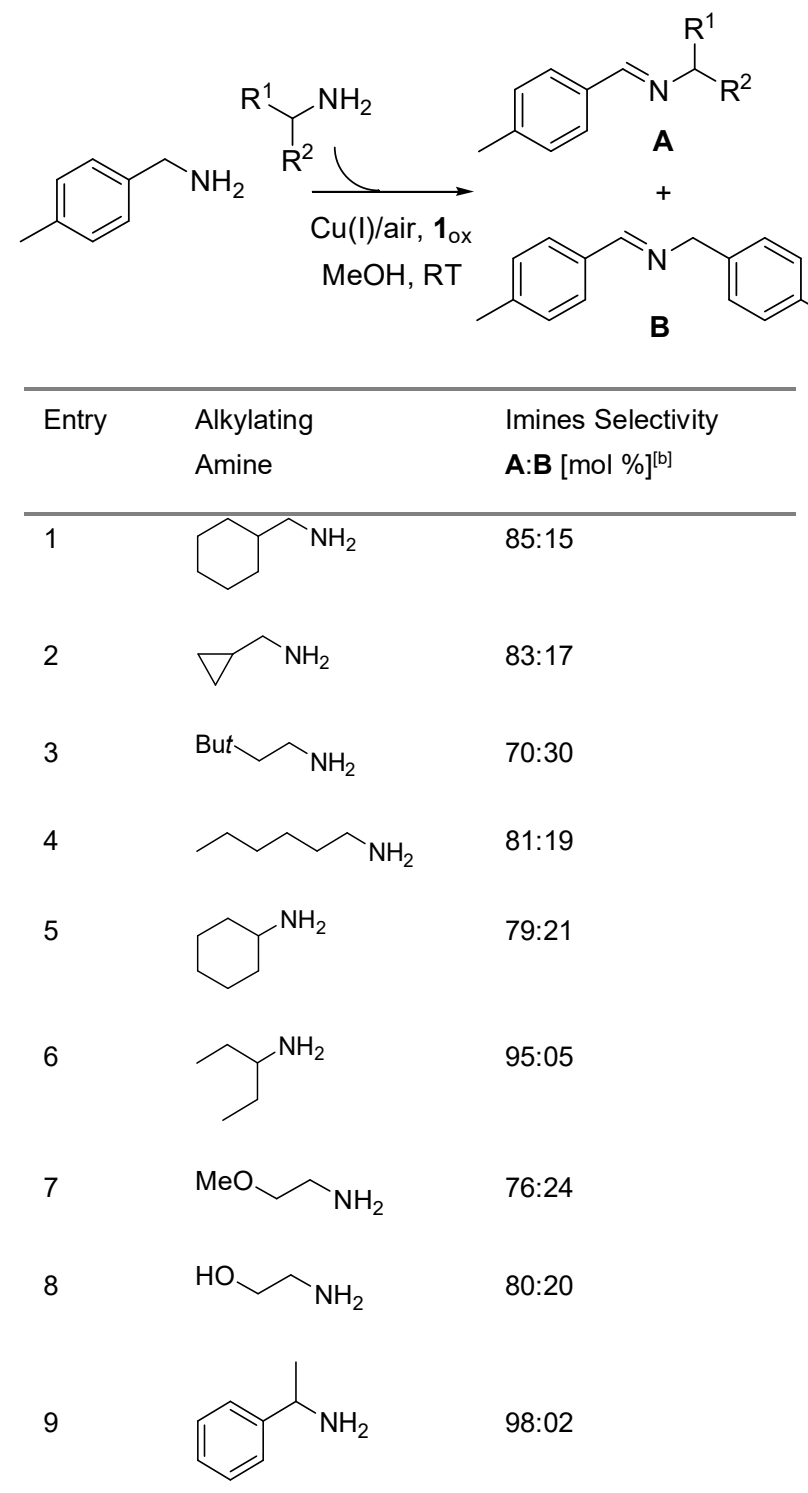

[a] Reagents and conditions: (4-methylbenzylamine) $=10 \mathrm{mM}$, (alkylating amine) $=10 \mathrm{mM},(1 \mathrm{ox})=0.4 \mathrm{mM}(4 \mathrm{~mol} \%$ relative to amine), Cu(I) : copper (I)-3-methylsalicylate $=0.04 \mathrm{mM}(0.4 \mathrm{~mol} \%$ relative to amine $), 10 \mathrm{~mL}$ of $\mathrm{MeOH}, 10 \mathrm{~h}, \mathrm{RT}$; the conversion of 4 -methylbenzylamine was roughly quantitative in all cases. [b] Selectivity based on ${ }^{1} \mathrm{H}$ NMR of crude product. 


\section{Captions for Schemes}

Scheme 1. Ionic transamination mechanism of catalytic oxidation of primary amines to imines mediated by electrogenerated $o$-iminoquinone amine oxidase mimic $\mathbf{1}_{\mathbf{o x}}$.

Scheme 2. $\mathrm{Cu}(\mathrm{I}) /$-iminoquinone $\mathbf{1}_{\mathrm{ox}}$ catalyzed aerobic oxidation of primary amines to imines. 


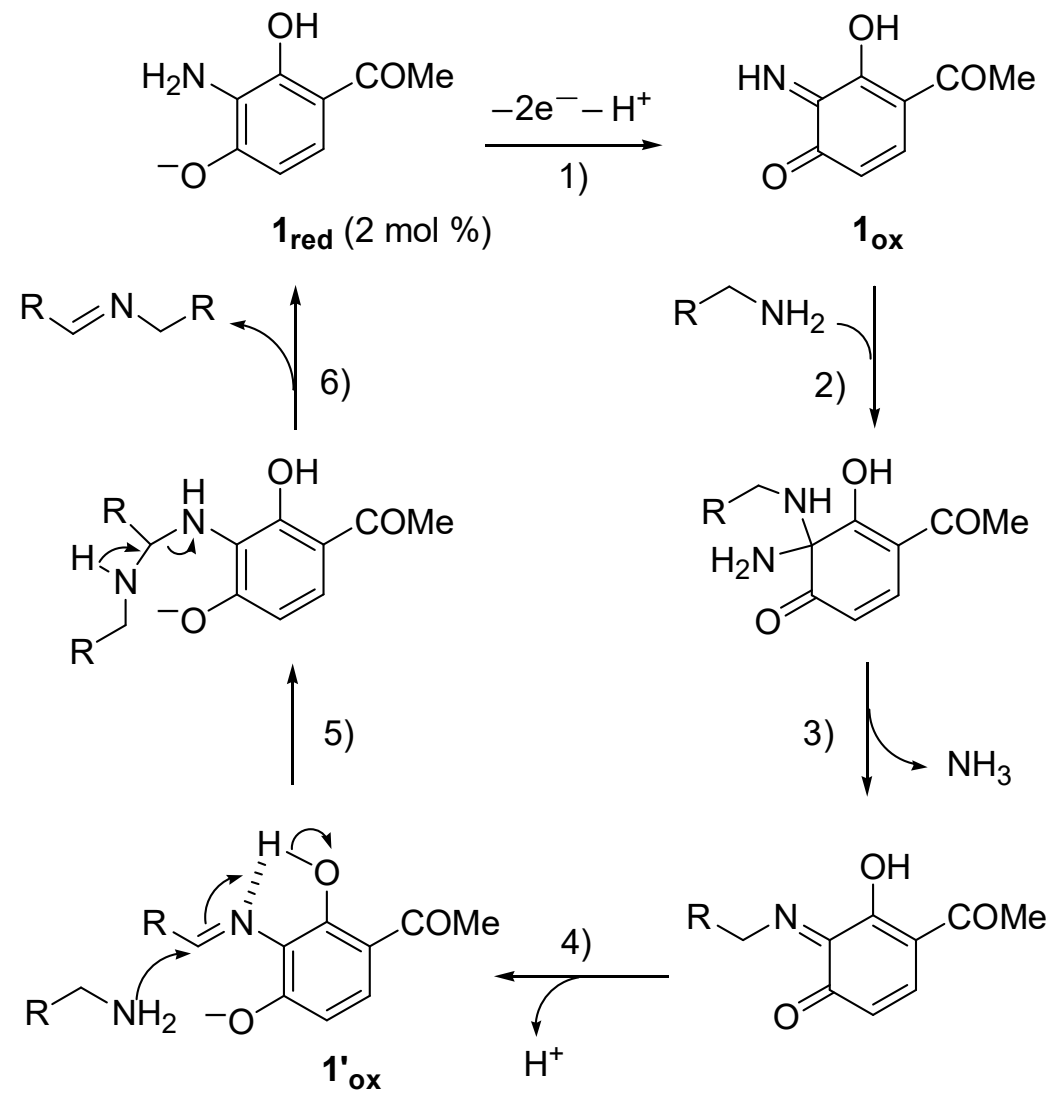

Scheme 1 


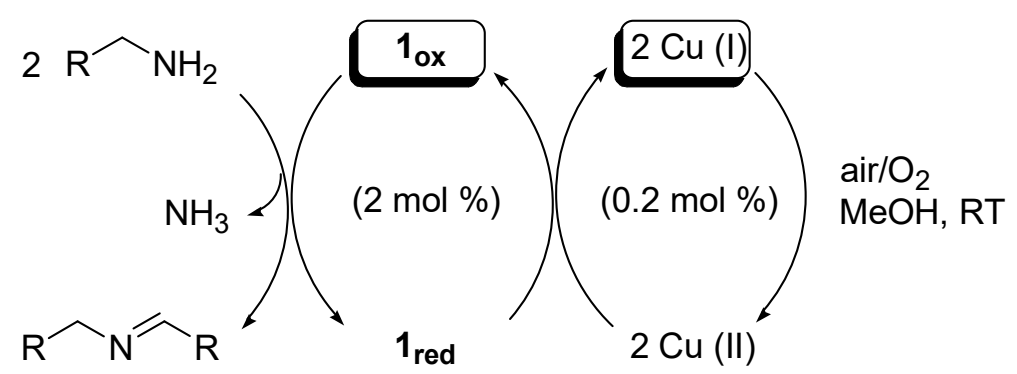

Scheme 2 


\section{Table of Contents}

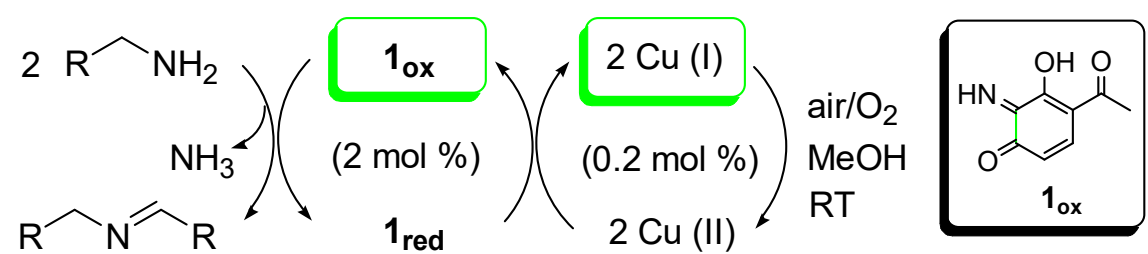

Acting together: Low catalytic amounts of $\mathrm{Cu}(\mathrm{I})(0.2 \mathrm{~mol} \%)$ and $\mathbf{1}_{\mathbf{o x}}(2 \mathrm{~mol} \%)$ are sufficient to activate the $\alpha-\mathrm{C}-\mathrm{H}$ bond of primary amines which are converted into alkylated imines under ambient conditions. This atom-economical green process tolerates the presence of various reactive functional groups and is highly selective in the case of cross-coupling of two amines. 